\title{
Notes on the vocalizations of Dunnock (Prunella modularis)
}

Peter Boesman

In the following we briefly analyze and compare voice of the different races of Dunnock (Prunella modularis). We also try to quantify the extent of any vocal differences using the criteria proposed by Tobias et al. (2010), as a support for taxonomic review.

We have made use of sound recordings available on-line from Xeno Canto (XC).

Our main interest is to compare voice of race obscura (which is moderately distinct and has a somewhat disjunct range) with other races.

We have located only two recordings of obscura, and to the ear these sound very similar to European races:

obscura $(n=2)$

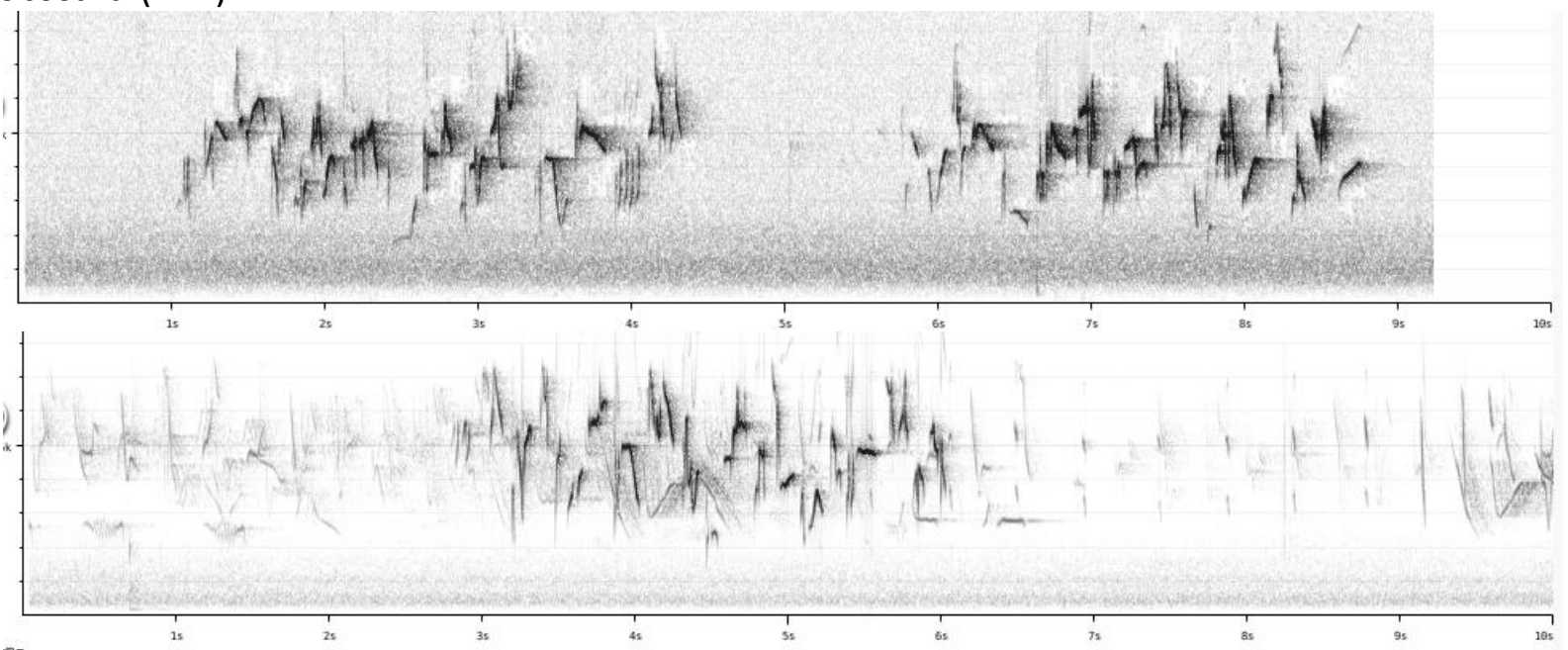

to be compared with other races. A few random examples:

France

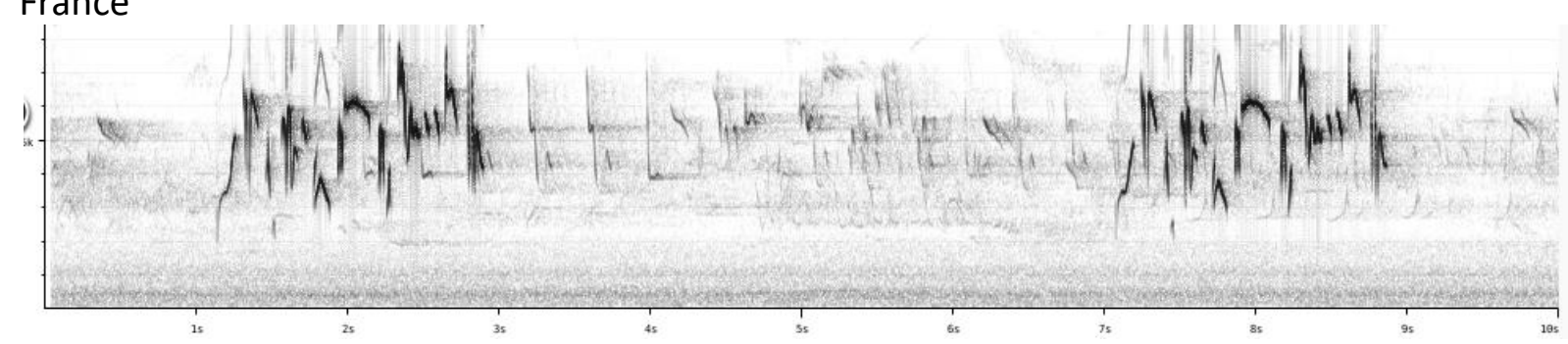

Germany

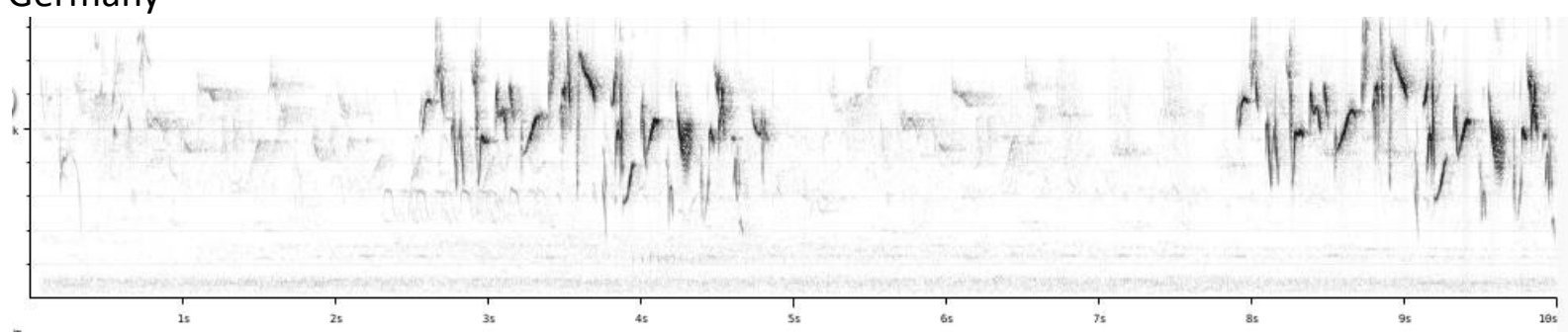




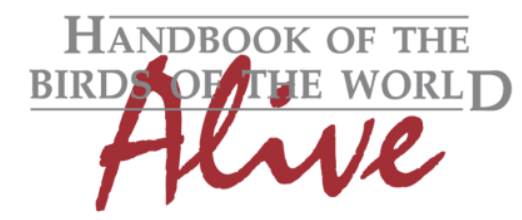

\section{ORNITHOLOGICAL NOTES}
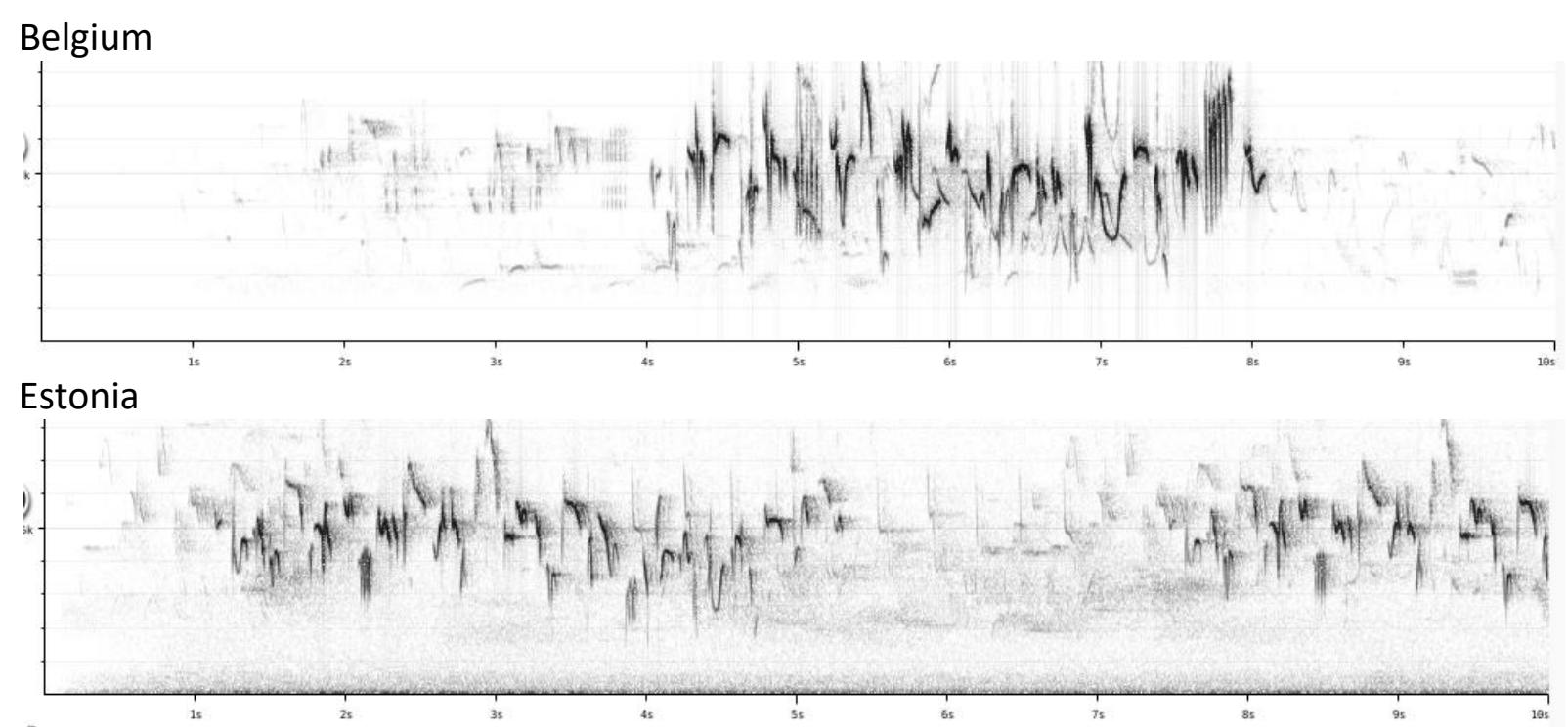

All basic sound parameters for song of obscura fall within the range of other races (phrase length, \# of notes, note length, frequency, pace,..).

Individual note shapes don't seem to be unique either, and overall pattern of a full song phrase rather similar as well.

Based on the available recordings, we can conclude that there are no clear vocal differences.

This note was finalized on 28th April 2016, using sound recordings available on-line at that moment. We would like to thank in particular the many sound recordists who placed their recordings for this species on XC, in particular Fernand Deroussen and Marcin Solowiej for recordings of race obscura.

\section{References}

Tobias, J.A., Seddon, N., Spottiswoode, C.N., Pilgrim, J.D., Fishpool, L.D.C. \& Collar, N.J. (2010). Quantitative criteria for species delimitation. Ibis 152(4): 724-746.

\section{Recommended citation}

Boesman, P. (2016). Notes on the vocalizations of Dunnock (Prunella modularis). HBW Alive Ornithological Note 344. In: Handbook of the Birds of the World Alive. Lynx Edicions, Barcelona. (retrieved from http://www.hbw.com/node/1252869 on 26 October 2016). 